\title{
Effect of Nano-HA/Collagen Composite Hydrogels on Osteogenic Behavior of Mesenchymal Stromal Cells
}

\author{
Astghik Hayrapetyan $^{1}$ - Matilde Bongio ${ }^{1}$ - Sander C. G. Leeuwenburgh ${ }^{1}$. \\ John A. Jansen ${ }^{1}$ • Jeroen J. J. P. van den Beucken ${ }^{1}$
}

Published online: 23 January 2016

(C) The Author(s) 2016. This article is published with open access at Springerlink.com

\begin{abstract}
This study aimed to comparatively evaluate the in vitro effect of nanosized hydroxyapatite and collagen (nHA/ COL) based composite hydrogels (with different ratios of nHA and COL) on the behavior of human mesenchymal stromal cells (MSCs), isolated from either adipose tissue (ATMSCs) or bone marrow (BM-MSCs). We hypothesized that (i) nHA/COL composite hydrogels would promote the osteogenic differentiation of MSCs in an nHA concentration dependent manner, and that (ii) AT-MSCs would show higher osteogenic potential compared to BM-MSCs, due to their earlier observed higher proliferation and osteogenic differentiation potential in 2D in vitro cultures [1]. The obtained results indicated that AT-MSCs show indeed high proliferation, differentiation and mineralization capacities in $\mathrm{nHA} / \mathrm{COL}$ constructs compared to BM-MSCs, but this effect was irrespective of nHA concentration. Based on the results of alkaline phosphatase (ALP) activity and osteocalcin (OCN) protein level, the osteogenic differentiation of BM-MSCs started in the beginning of the culture period and for AT-MSCs at the end of the culture period. At a molecular level, both cell types showed high expression of osteogenic markers (bone morphogenic protein 2 [BMP2], runt-related transcription factor 2 [RUNX2], OCN or COL1) in both an nHA concentration and time dependent manner. In conclusion, AT-MSCs demonstrated higher osteogenic potential in nHA/COL based 3D micro-environments compared to BM-MSCs, in which proliferation and osteogenic differentiation were highly promoted in a time dependent manner, irrespective of nHA amount in
\end{abstract}

Jeroen J. J. P. van den Beucken jeroen.vandenbeucken@radboudumc.nl

1 Department of Biomaterials, Radboudumc, Ph van Leijdenlaan 25, 6525 ex Nijmegen, The Netherlands the constructs. The fact that AT-MSCs showed high proliferation and mineralization potential is appealing for their application in future pre-clinical research as an alternative cell source for BM-MSCs.

Keywords Calcium phosphate · Composite hydrogels · AT-MSCs · BM-MSCs · Osteogenic differentiation

\section{Introduction}

Bone loss, caused by trauma, tumor resection or congenital disorders, is an increasingly serious health problem, for which current treatment remains a clinical challenge, especially for critical size bone defects [2]. Structurally, bone tissue forms the human skeleton, which consists of multiple cell types and a largely mineralized extracellular matrix (ECM). The organic part of ECM is composed of protein fibers (mainly type 1 collagen), which represents about $30 \mathrm{wt} \%$ of bone. The inorganic part of bone is composed of minerals $(\sim 70 \mathrm{wt} \%$ of bone), with hydroxyapatite $\left(\mathrm{HA} ; \mathrm{Ca}_{10}\left(\mathrm{PO}_{4}\right)_{6}(\mathrm{OH})_{2}\right)$ as the major component [3, 4]. As such, the weight ratio between collagen and HA is approximately 1:2. These HA crystals, embedded within the extracellular matrix, are very small, measuring approximately $200 \AA$ (in the largest dimension, i.e. nano-sized HA, nHA) [5]. In a synergistic manner, the strands of collagen provide bone with tensile strength and the interspersed nHA crystals provide compressional strength [5].

Nowadays in bone regenerative research, the use of scaffold systems receives remarkable attention, because of the increasing demand to replace autologous bone for grafting purposes. For an appropriate cell attachment, proliferation and osteogenic differentiation, scaffolds need to meet several requirements, e.g. biocompatibility, ability of fluid transport, 
delivery of bioactive molecules, surface topographical cues, degradability and ability to induce signal transduction [6].

In view of biomimicry, it seems appealing to develop scaffolds that combine structural properties of bone ECM. Among the different materials available for scaffold preparation, hydrogels represent a highly versatile group of biomaterials with appealing properties for 3D scaffolding. Hydrogels are hydrophilic networks (water content $\geqslant 30 \%$ by weight) of natural or synthetic polymer chains, which approximate the viscoelastic properties of native tissue [7]. Because of distinctive features, such as biocompatibility, cell-controlled degradability, injectability and ability to release drugs or bioactive molecules, hydrogels are considered as reliable biomaterials for the regeneration of a wide range of tissues, including cartilage and bone $[6,8]$. The advantages of natural hydrogels (i.e. collagen, fibrin) include among others their non antigenic and intrinsic cellular interaction capacities [9]. Moreover, collagen based hydrogels support the expression of an osteogenic phenotype of (differentiating) MSCs in vivo [10]. However, the mechanical properties of collagen are relatively low $(\mathrm{E} \sim 100 \mathrm{MPa})$ in comparison to bone $(\mathrm{E} \sim 2-50 \mathrm{GPa})$ [11]. To obtain more biomimetic scaffold systems for bone regeneration, several attempts have focused on the combination of a hydrogel and HA to study effects of cell behavior (mainly mesenchymal stromal cells, MSCs) in vitro and bone regeneration in vivo [12-14]. These studies have shown that HA/ collagen based composite hydrogels can have potential to enhance MSC osteogenic differentiation [8, 15].

From a cellular perspective, hydrogels provide a 3D microenvironment to which cells can attach, attain a specific morphology, have 3D cell-cell/cell-biomaterial interactions and subsequently proliferate and differentiate [16]. Moreover, for bone regeneration, the use of cell-based constructs provides osteoinductive properties $[17,18]$ in comparison to bare scaffolds $[19,20]$. Since in the developmental and regenerative processes of bone BM-MSCs are involved, they have become the main cell source for bone tissue engineering [21]. However, MSCs can be extracted from different tissues, such as skin, muscle, periodontal ligament, blood, adipose tissue (AT) and the yield of extracted cells is dependent of cell source. The easiest harvesting of MSCs (less invasive) with substantial yield is from adipose tissue $[1,22]$. Moreover, at the same $2 \mathrm{D}$ culture condition (using platelet lysate [PL] or fetal bovine serum [FBS] as nutritional supplement), AT-MSCs showed higher proliferation and osteogenic differentiation capacities compared to BM-MSCs, and AT-MCSs showed their highest proliferation and osteogenic differentiation capacities in PL supplemented media, whereas BM-MSCs did in FBS supplemented media $[1,23]$. In view of this, the major challenge remains to understand the complexity of cellular responses of different MSCs to different scaffold systems.

The aim of this study was to comparatively evaluate the in vitro effect of biomimetic $\mathrm{nHA} /$ collagen based composite hydrogels (with different ratios of nHA) on the behavior of human MSCs, isolated from adipose tissue (AT-MSCs) or bone marrow (BM-MSCs). We hypothesized that (i) nHA/ collagen based hydrogels will promote the osteogenic differentiation of MSCs in an nHA concentration dependent manner, (ii) AT-MSCs will show higher osteogenic potential compared to BM-MSCs, because of their intrinsic higher proliferation and osteogenic differentiation potential in $2 \mathrm{D}$ in vitro cultures.

\section{Materials and Methods}

\section{Cell Culture}

AT-MSCs were isolated from fat tissue of healthy human donors. The fat tissue was obtained from the Department of Plastic Surgery (Radboudumc, The Netherlands) after written informed consent. BM-MSCs were isolated from human iliac bone chips, obtained from patients undergoing maxillofacial surgery at the Department of Oral and Craniofacial Surgery (Radboudumc, The Netherlands) after written informed consent. MSC extraction was performed according to the principles of the Declaration of Helsinki. The isolation procedure of AT-MSCs and BM-MSCs is described in detail elsewhere [1, 24-26]. Harvested cells were examined by fluorescenceactivated cell sorting (FACS) for positive expression of CD73, CD90 and CD105 (eBioscience, San Diego, USA) and negative expression of CD45 (R\&D system, Abingdon, United Kingdom). Next, both cell types were examined (via biochemical assays) for their osteogenic potential, i.e. ALP activity and calcium deposition.

Upon usage, MSCs were cultured in corresponding proliferation media consisting of alpha Minimal Essential Medium, $\left(\alpha\right.$-MEM; Gibco ${ }^{\circledR}$, Life Technologies, Grand Island, USA) supplemented either with $5 \%$ PL (Sanquin Blood Bank, The Netherlands) for AT-MSCs or with $15 \%$ fetal bovine serum (FBS; Lonza, Basel, Switzerland) for BM-MSCs [1], at $37^{\circ} \mathrm{C}$ in humid atmosphere with $5 \% \mathrm{CO}_{2}$ (the complete composition of proliferation media is given in Table 1). Medium was changed twice a week. Cells were passaged upon reaching $\sim 80 \%$ confluency using $0.25 \% \mathrm{w} / v$ trypsin $/ 0.02 \%$ EDTA $\left(\right.$ Gibco $\left.^{\circledR}\right)$.

\section{Preparation of Hydrogels and Experimental Groups}

Prior to the preparation of hydrogel scaffolds, nHA crystals (size: 20-500 nm; Berkeley Advanced Biomaterials, Berkeley, CA, USA) were suspended in PBS $(10 \times$ concentrated $)$ at a final concentration of $150 \mathrm{mg} / \mathrm{ml}$. The suspension was homogenized by sonication for $20 \mathrm{~min}$. Before addition to hydrogels (see Table 2), this suspension was vortexed for $1 \mathrm{~min}$. For the preparation of hydrogels, collagen type 1 
Table 1 Composition of the proliferation media (PM) and osteogenic media (OM)

\begin{tabular}{ll}
\hline BM-MSCs & AT-MSCs \\
Minimal Essential Medium ( $\alpha$-MEM) & Minimal Essential Medium ( $\alpha$-MEM) \\
\hline FBS-supplemented (PM-FBS) & PL-Supplemented (PM-PL) \\
$15 \%$ fetal bovin serum (FBS) & $5 \%$ platelet lysate (PL) \\
$0.2 \mathrm{mM}$ L-ascorbic acide 2-phosphate (Vit C) & $10 \mathrm{U} / \mathrm{ml}$ heparin \\
$2 \mathrm{mM} \mathrm{L-glutamine}$ & $100 \mathrm{U} / \mathrm{ml}$ penicillin \\
$100 \mathrm{U} / \mathrm{ml}$ penicillin & $10 \mu \mathrm{g} / \mathrm{ml}$ streptomycin \\
$10 \mu \mathrm{g} / \mathrm{ml}$ streptomycin & \\
FBS-supplemented (OM-FBS) & PL-Supplemented (OM-PL) \\
$15 \%$ fetal bovin serum (FBS) & $5 \%$ platelet lysate (PL) \\
$0.2 \mathrm{mM}$ L-ascorbic acide 2-phosphate (Vit C) & $0.2 \mathrm{mM}$ L-ascorbic acide 2-phosphate (Vit C) \\
$2 \mathrm{mM}$ L-glutamine & $2 \mathrm{mM} \mathrm{L-glutamine}$ \\
$100 \mathrm{U} / \mathrm{ml}$ penicillin & $100 \mathrm{U} / \mathrm{ml}$ penicillin \\
$10 \mu \mathrm{g} / \mathrm{ml}$ streptomycin & $10 \mu \mathrm{g} / \mathrm{ml}$ streptomycin \\
$10-8 \mathrm{M}$ dexamethasone & $10-8 \mathrm{M}$ dexamethasone \\
$0.01 \mathrm{M} \beta$-glycerophosphate & $0.01 \mathrm{M} \beta$-glycerophosphate \\
& $0.0210 \mathrm{U} / \mathrm{ml}$ heparin \\
\hline
\end{tabular}

(COL; rat tail; BD Bioscience, Bedford MA, USA) was used with various amounts of nHA (Table 2). The procedure of hydrogel preparation was according to the manufacturer's instruction (Table 2), and composite nHA/COL hydrogels were prepared with an nHA/COL ratio (wt/wt) of $0 / 1,1 / 1$, and 2/1. MSCs were added during hydrogel preparation (Table 2). Cell seeding density of AT-MSCs and BM-MSCs in all experimental groups was $1 \times 10^{6}$ per $1 \mathrm{ml}$ of hydrogels (Table 3 ).
Table 2 Reagents for scaffold preparation and cell encapsulation

\begin{tabular}{|c|c|c|c|c|}
\hline \multirow{2}{*}{$\begin{array}{l}\text { Groups } \\
\text { CaP/Collagen 0:1 (control) }\end{array}$} & \multicolumn{2}{|l|}{ A. Without cells } & \multicolumn{2}{|c|}{ B. With the cells } \\
\hline & Reagents & Volume $(\mu \mathrm{L})$ & Reagents & Volume $(\mu \mathrm{L})$ \\
\hline & Collagen & 2610 & Collagen & 2610 \\
\hline & $\operatorname{PBS}(10 \times)$ & 300 & $\operatorname{PBS}(10 \times)$ & 300 \\
\hline & CaP susp. & - & CaP susp. & - \\
\hline & $\mathrm{NaOH} 1 \mathrm{~N}$ & 60 & $\mathrm{NaOH} 1 \mathrm{~N}$ & 60 \\
\hline & $\mathrm{H}_{2} \mathrm{O} / \alpha-\mathrm{MEM}$ & 30 & $\mathrm{H}_{2} \mathrm{O} / \alpha-\mathrm{MEM}$ & 0 \\
\hline & Cell susp. & - & Cell susp. & 30 \\
\hline & Total & $3000 \mu \mathrm{l}$ & Total & $3000 \mu \mathrm{l}$ \\
\hline \multirow[t]{8}{*}{$\mathrm{CaP} /$ Collagen 1:1 } & Reagents & Volume $(\mu \mathrm{L})$ & Reagents & Volume $(\mu \mathrm{L})$ \\
\hline & Collagen & 2610 & Collagen & 2610 \\
\hline & $\operatorname{PBS}(10 \times)$ & 240 & $\operatorname{PBS}(10 \times)$ & 240 \\
\hline & $\mathrm{CaP}$ susp. & $60(150 \mathrm{mg} / \mathrm{ml})$ & CaP susp. & $60(150 \mathrm{mg} / \mathrm{ml})$ \\
\hline & $\mathrm{NaOH} 1 \mathrm{~N}$ & 60 & $\mathrm{NaOH} 1 \mathrm{~N}$ & 60 \\
\hline & $\mathrm{H}_{2} \mathrm{O} / \alpha-\mathrm{MEM}$ & 30 & $\mathrm{H}_{2} \mathrm{O} / \alpha-\mathrm{MEM}$ & 0 \\
\hline & Cell susp. & - & Cell susp. & 30 \\
\hline & Total & $3000 \mu \mathrm{l}$ & Total & $3000 \mu \mathrm{l}$ \\
\hline \multirow[t]{8}{*}{$\mathrm{CaP} /$ Collagen 2:1 } & Reagents & Volume $(\mu \mathrm{L})$ & Reagents & Volume $(\mu \mathrm{L})$ \\
\hline & Collagen & 2610 & Collagen & 2610 \\
\hline & $\operatorname{PBS}(10 \times)$ & 180 & $\operatorname{PBS}(10 \times)$ & 180 \\
\hline & CaP susp. & $120(150 \mathrm{mg} / \mathrm{ml})$ & $\mathrm{CaP}$ susp. & $120(150 \mathrm{mg} / \mathrm{ml})$ \\
\hline & $\mathrm{NaOH} 1 \mathrm{~N}$ & 60 & $\mathrm{NaOH} 1 \mathrm{~N}$ & 60 \\
\hline & $\mathrm{H}_{2} \mathrm{O} / \alpha-\mathrm{MEM}$ & 30 & $\mathrm{H}_{2} \mathrm{O} / \alpha-\mathrm{MEM}$ & \\
\hline & Cell susp. & - & Cell susp. & 30 \\
\hline & Total & $3000 \mu \mathrm{l}$ & Total & $3000 \mu \mathrm{l}$ \\
\hline
\end{tabular}


Table 3 Schematic overview of the experimental groups used with varying CaP-particle content (Ca) and with/- cells

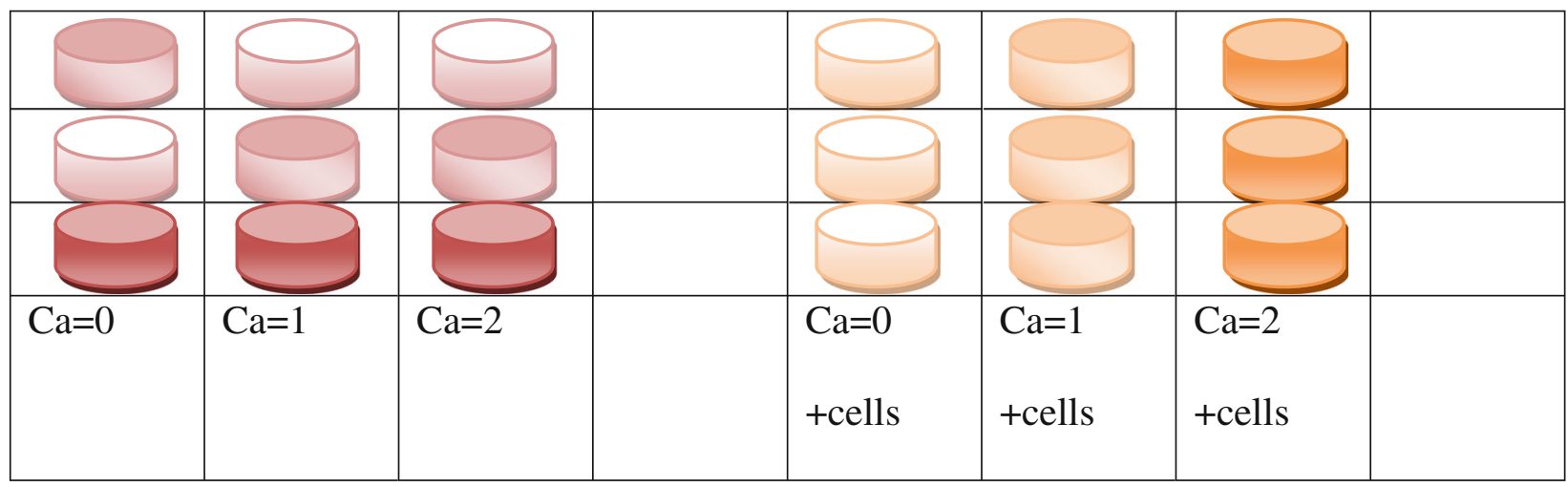

For the analysis of cellular behavior (DNA content, ALP activity and calcium [Ca] deposition) and histological analysis (HE staining, Von Kossa staining and immunohistochemistry [IHC]) hydrogels were injected in 48 well plates, with the total hydrogel volume of $200 \mu \mathrm{l}$ (200.000 cells; $n=3$ ). To obtain sufficient RNA, hydrogels for RNA extraction were injected in 24 well plates, with the total volume of $400 \mu \mathrm{l}(400.000$ cells; $n=3$ ). All samples were incubated in corresponding osteogenic media (Table 1), supplemented with either $5 \%$ PL for AT-MSCs or $15 \%$ FBS for BM-MSCs and incubated for 35 days at $37{ }^{\circ} \mathrm{C}$ in a humid atmosphere with $5 \% \mathrm{CO}_{2}$. To monitor the behavior of pure hydrogels (without cells) as a negative control $\mathrm{nHA} / \mathrm{COL}=0 / 1, \mathrm{nHA} / \mathrm{COL}=1 / 1, \mathrm{nHA} /$ $\mathrm{COL}=2 / 1$ constructs were prepared and cultured either in $\mathrm{PL}$ or in FBS supplemented media. Cell morphology was monitored with an inverted light microscope (Leica DM-IL, 5 W LED illumination, Rijswijk, The Netherlands).

\section{Cell Behavior}

To monitor cellular behavior, cellular DNA content, alkaline phosphatase (ALP) activity and calcium deposition were analyzed [1]. Samples were collected (at days 1, 14, 28 and 35) in $1 \mathrm{ml}$ MilliQ and subsequently stored at $-80{ }^{\circ} \mathrm{C}$ until use. The same samples were used for all biochemical assays. For extraction of cells from hydrogels, scaffolds were digested first using Collagenase A (Roche Diagnostics Penzberg, Germany). According to the manufacturer's instruction, a digestion buffer was prepared in a concentration of $1 \mathrm{mg} / \mathrm{ml}$. Before digestion, the constructs were washed 2 times with PBS, incubated with $1 \mathrm{ml}$ digestion buffer overnight at $37{ }^{\circ} \mathrm{C}$ on a rotary shaker. After complete digestion and two repetitive freeze/thaw cycles at $-80{ }^{\circ} \mathrm{C} /+20^{\circ} \mathrm{C}$, samples were ready for the analysis of DNA content, ALP activity and Ca deposition $[1,27]$. The results of ALP content were normalized by the corresponding cellular dsDNA amount. After analyzing DNA content and ALP activity, samples were doubled in volume using $1 \mathrm{~N}$ acetic acid (to dissolve mineral deposits) and incubated at room temperature overnight. Ca deposition was measured as described previously [28].

\section{Cellular DNA Content}

Cellular DNA content was measured using a QuantiFluor ${ }^{\circledR}$ dsDNA System Kit (Promega, Madison, Wisconsin, USA). For the standard curve, serial dilutions of dsDNA stock (range: 0-2000 ng/ml) were prepared. $100 \mu \mathrm{l}$ of either sample of standard solution was added into the wells, followed by $100 \mu \mathrm{l}$ of working solution. The plate was incubated at room temperature for $5 \mathrm{~min}$, and then the absorbance of samples/ standards was measured at $504 \mathrm{~nm}$ excitation and $541 \mathrm{~nm}$ emission, using a fluorescence microplate reader (FL600, BioTek, Canada).

\section{Alkaline Phosphatase (ALP) Activity}

ALP activity was measured using a $5 \mathrm{nM}$ p-nitrophenyl phosphate (4-NP) colorimetric assay. The procedure was according to the manufacturer's instruction (Sigma-Aldrich, St. Louis, MO, USA). Briefly, $80 \mu \mathrm{l}$ of sample solution was combined with $20 \mu \mathrm{l}$ of buffer (0.5 M 2-amino-2methyl-1-propanol). A standard curve was prepared with serial dilutions of 4-NP, in a range of 0 $25 \mathrm{nmol}$. Next, $100 \mu \mathrm{l}$ substrate solution (5 nM p-nitrophenyl phosphate) was added to the samples/standards and incubated for $60 \mathrm{~min}$ at $37^{\circ} \mathrm{C}$. The reaction was stopped by adding to each well $50 \mu \mathrm{l} 0.3 \mathrm{M} \mathrm{NaOH}$ and the absorbance of samples was measured at $405 \mathrm{~nm}$ using an ELISA microplate reader (EL800, BioTek, Abcoude, The Netherlands). ALP activity was normalized for corresponding cellular dsDNA amount.

\section{Calcium Deposition}

Calcium deposition was measured using the orthocresolphtalein complexone assay (OCPC; Sigma Aldrich, St. Louis, MO, USA), which is based on a colorimetric reaction between o-cresolphthalein complexone and calcium. 
The assay was performed according to the manufacturer's instruction. For the standard curve, serial dilutions of calcium stock $\left(\mathrm{CaCl}_{2}\right)$ were prepared (range: $\left.0-100 \mathrm{mg} / \mathrm{ml}\right)$. Next, $10 \mu \mathrm{l}$ of sample or standard was used, to which $300 \mu \mathrm{l}$ OCPC solution was added to complete the reaction. After the incubation of the plate for $10 \mathrm{~min}$ at room temperature, the absorbance was measured at $570 \mathrm{~nm}$ using an ELISA microplate reader (EL800, BioTek, Canada).

\section{RNA Isolation and Reverse Transcription}

To analyze gene expression profiles of selected genes, cellular RNA was isolated using Tryzol method in combination with the Genelute Mammalian Total RNA Miniprep Kit (SigmaAldrich). Samples were collected (at days 0, 14, 28 and 35) in $1 \mathrm{ml}$ TRIzol lysis buffer and subsequently stored at $-80{ }^{\circ} \mathrm{C}$ until RNA extraction. After extraction, RNA was quantified using a spectrophotometer (Nanodrop Technologies, Wilmington, DE, USA). For reverse transcription (cDNA synthesis), an iScript ${ }^{\mathrm{TM}}$ cDNA kit was used (Bio-Rad, Hercules, CA, USA), and for each cDNA reaction $1 \mu \mathrm{g}$ of RNA was used. The samples were stored at $-20^{\circ} \mathrm{C}$ until use.

\section{Real-Time Polymerase Chain Reaction}

For real-time polymerase chain reaction (RT-PCR), qPCR Master Mix Plus/SYBR Green I (Eurogentec; Seraing, Belgium) was used. RT-PCR was completed with 40 amplification cycles. The sequence of applied primers is given in Table 4. The raw data were normalized to the expression of Ribosomal Protein Large P0 (RPLP0 housekeeping gene) within the same sample/RNA [29]. Gene expression level and fold changes were calculated according to Livak \& Schmittgen $\left(2^{-\Delta \Delta C t}\right)$ relative subsequently to AT-MSCs or BM-MSCs at the day 0 [30]. The genes of interest were Osteocalcin (OCN), Bone Morphogenetic Protein 2 (BMP2), Runt-related Transcription Factor 2 (RUNX2), and Collagen type 1 (COL1).

Table 4 Primer sequences for RT-PCR

\begin{tabular}{ll}
\hline Gene name & Sequences \\
\hline RPLP0 & Forward-TTCTTCTTTGGGCTG GTCAT \\
& Reverse-TTGGGTAGCCAATCTGCAGA \\
RUNX2 & Forward-TCTGGCCTTCCACTCTCAGT \\
& Reverse-GACTGGCGGGGTGTAAGTAA \\
BMP-2 & Forward-CCCAGCGTGAAAAGAGAGAC \\
& Reverse-GGAAGCAGCAACGCTAGAAG \\
COL1 & Forward-GGTGTAAGCGGTGGTGGTTAT \\
& Reverse-AGGTTCCCCGTTCTCACTTT \\
OCN & Forward- GGCGCTACCTGTATCAATGG \\
& Reverse-GTGGTCAGCCAACTCGTCA \\
\hline
\end{tabular}

\section{Histological Analysis and Immunohistochemistry}

Samples for histological analysis and IHC were collected at day 7 and 28, fixed at $10 \%$ formalin, decalcified in $4 \%$ EDTA for $\sim 2$ weeks, and regularly checked with X-ray for the level of remaining mineral content in the constructs. After complete demineralization, samples were dehydrated in a graded series of ethanol (70-100 \%) and embedded in paraffin. Simultaneously, human bone chips (obtained from the Department of Maxillofacial surgery, Radboudumc, Nijmegen, The Netherlands; after written informed consent), were processed as a control for all stains. Sections with a thickness of $6 \mu \mathrm{m}$ were prepared using a standard microtome (RM2165; Leica, Nussloch, Germany). To analyze cell distribution in hydrogels, every 10th slide was stained with hematoxylin/eosin (HE). To identify phosphate groups in mineralized matrix, separate slides were prepared for Von Kossa staining, which were stained first with $5 \%$ silver nitrate $\left(\mathrm{AgNO}_{3}\right)$, washed with distilled water, dehydrated again, and fixed with $5 \%$ sodium thiosulfate $\left(\mathrm{Na}_{2} \mathrm{~S}_{2} \mathrm{O}_{3}\right)$.

Subsequently, continuous tissue sections were used to monitor osteogenic differentiation of cells in hydrogels. As an osteogenic marker, osteocalcin (OCN, rabbit antimouse osteocalcin) protein was cheeked by IHC. Sections were de-paraffinised, rehydrated and rinsed in PBS. Next, samples were fixed for $10 \mathrm{~min}$ in $10 \%$ hydrogen peroxide (stock)/methanol solution. Afterwards, samples were pre-incubated for $10 \mathrm{~min}$ with $10 \%$ normal donkey serum (NDS) and then incubated with the primary antibody $(1: 1600)$ overnight at $4{ }^{\circ} \mathrm{C}$. Subsequently, sections were washed $3 \times$ with PBS, and incubated with secondary antibody, anti mouse IgG (host donkey) conjugated with biotin (Jackson ImmunoResearch, West Baltimore Pike, West Grove, PA, USA) for $60 \mathrm{~min}$. After washing, the peroxidase conjugates were visualized with 3'3diaminobenzidine (DAB) substrate (Envision kit; Dako Cytomation) for $10 \mathrm{~min}$ at room temperature, and nuclei were stained for $10 \mathrm{~s}$ with hematoxilin.

\section{Statistical Analysis}

Data are presented as mean \pm standard deviation. Statistical analysis was performed based on $\mathrm{N}=3$ (for all experimental groups) with Graphpad Prism ${ }^{\circledR} 5.03$ software (Graphpad Software Inc., San Diego, CA, USA). Quantitative results were analyzed using a one-way ANOVA with a Posthoc Dunnett test (using either nHA/ $\mathrm{COL}=0 / 1$ or day 7 [for biochemical assays] and day 14 [for Q-PCR analysis] data as control). Differences were considered significant at $p<0.05$. All experiments were repeated 4 times. 
Fig. 1 Cell morphology of ATMSCs or BM-MSCs monitored with inverted light microscopy in different nHA/COL constructs, after 3 days of culture

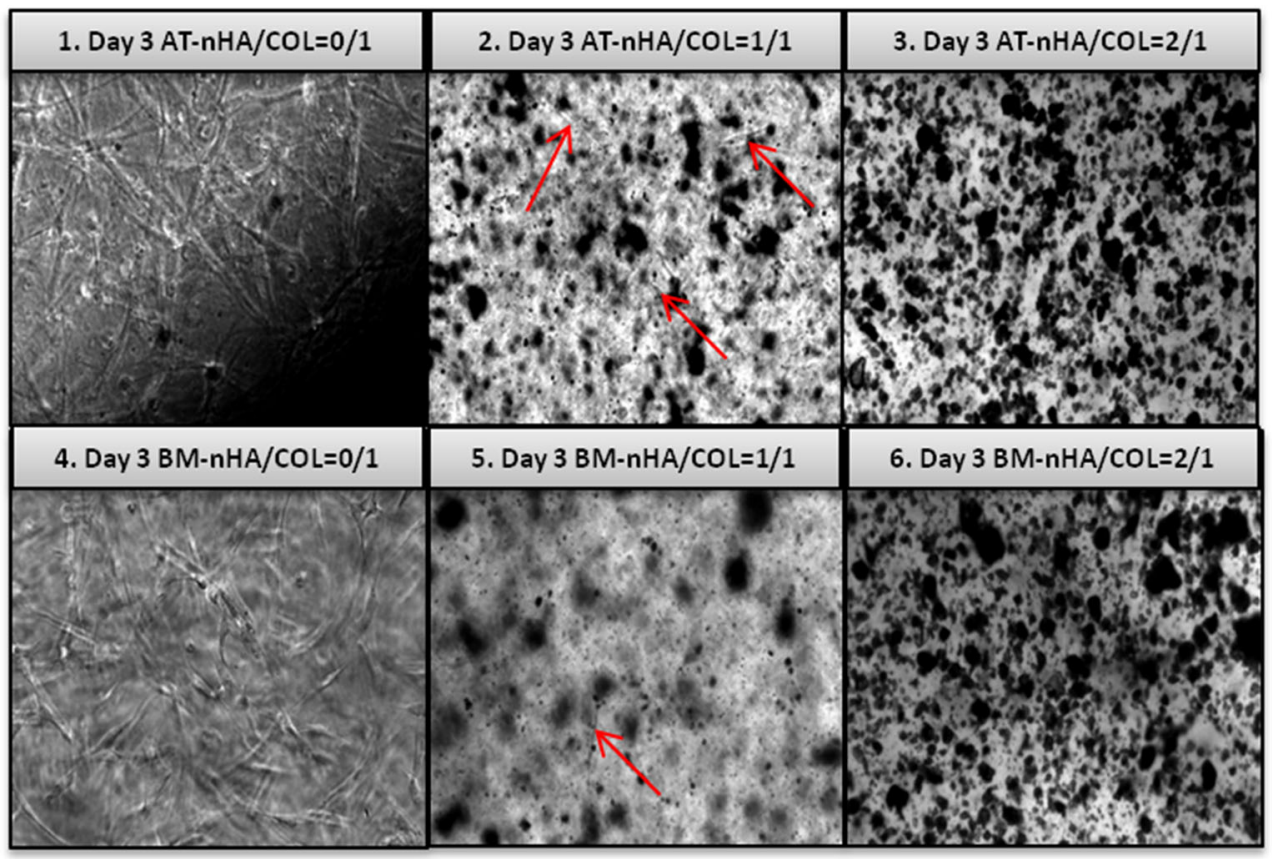

\section{Results}

The results of FACS analysis showed that both cell types (AT-MSCs and BM-MSCs) were $99 \%$ positive for expression of stem cell surface markers CD73, CD90 and CD105, whereas both these cell types were completely negative for the hematopoietic marker CD45 (data not shown).
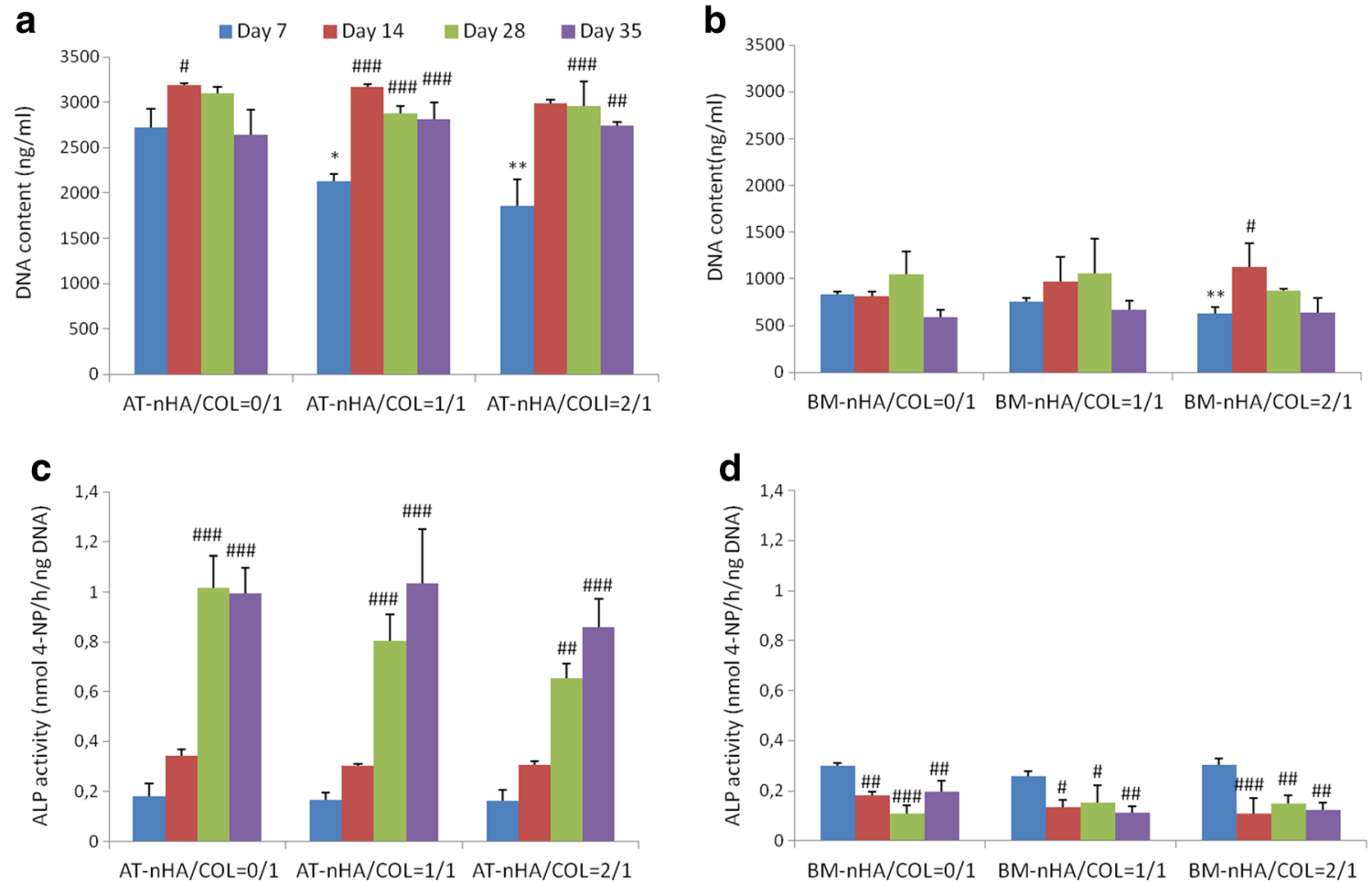

Fig. 2 Cellular behavior of MSCs in different nHA/COL constructs. a Cellular DNA content of AT-MSCs, $\mathbf{b}$ Cellular DNA content BM-MSCs c ALP-activity of AT-MSCs, (D) ALP-activity of BM-MSCs. The "*” indicates significantly different compared to $\mathrm{nHA} / \mathrm{COL}=0 / 1$ control, at indicates significantly different compared to day 7 ( $p$-values: ${ }^{*} p<0.05$, $\#^{\#} p<0.01,{ }^{\# \#} p<0.001$ ) 


\section{Cell Morphology}

Light microscopy analysis showed that both AT-MSCs and BM-MSCs were able to survive in nHA/COL constructs (Fig. 1). Both cell types showed an elongated, spindleshaped morphology in these constructs, but from 3 days of culture onward, AT-MSCs visually appeared at higher cell density than BM-MSCs. After 7 days, hydrogels changed their shape and morphology, becoming dense and no longer transparent for light microscopy evaluation. The constructs shrunk drastically by changing diameter size about 2-fold (from $\sim 11 \mathrm{~mm}$ to $\sim 4-5 \mathrm{~mm}$ ).

\section{Cellular Behavior}

\section{Cellular DNA Content}

AT-MSCs showed a gradual increase in cell proliferation until day 14 (Fig. 2a). A significant temporal increase in cellular DNA content (relative to day 7) was observed for AT-nHA/ $\mathrm{COL}=0 / 1$ at day $14(p<0.05)$, AT-nHA/COL $=1 / 1$ at day 14 , $28,35(p<0.001)$, and AT-nHA/COL $=2 / 1$ at day 14 , $(p<0.001)$. Relative to AT-nHA/COL $=0 / 1$, at day 7 , a significantly lower cellular DNA content was observed for AT-
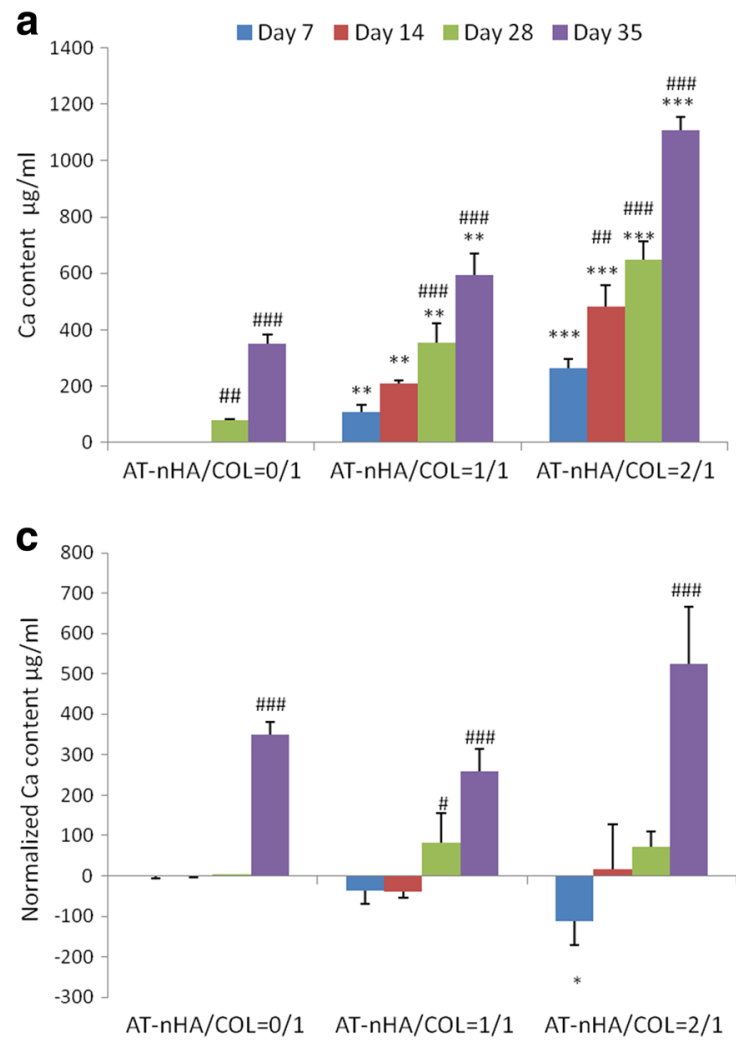

Fig. $3 \mathrm{Ca}$ deposition of MSCs in different nHA/COL constructs. a $\mathrm{Ca}$ deposition of AT-MSCs, $\mathbf{b}$ Ca deposition of BM-MSCs $\mathbf{c}$ Normailzed Ca deposition of AT-MSCs, $\mathbf{d}$ Normailzed Ca deposition of BM-MSCs. The "** indicates significantly different compared to $\mathrm{nHA} / \mathrm{COL}=0 / 1$ control,
$\mathrm{nHA} / \mathrm{COL}=1 / 1(p<0.05)$ and AT-nHA/COL $=2 / 1$ $(p<0.01)$.

BM-MSCs (Fig. 2b), showed limited cell proliferation over the entire culture period. Relative to day 7, a significant increase in cellular DNA content was observed only for BM$\mathrm{nHA} / \mathrm{COL}=2 / 1$ at day $14(p<0.05)$.

\section{ALP Activity}

AT-MSCs showed a gradual increase in ALP-activity (early marker for osteogenic differentiation) until the end of the culture period, irrespective of construct type (Fig. 2c). A significant increase in ALP-activity (relative to day 7) was observed for AT-nHA/COL $=0 / 1$ and AT-nHA/COL $=1 / 1$ at day 28 and $35(p<0.001)$, and AT-nHA/COL $=2 / 1$ at days $28(p<0.01)$ and $35(p<0.001)$. Relative to AT-nHA/COL $=0 / 1$, no significant differences were observed for AT-nHA/COL $=1 / 1$ and $\mathrm{AT}-\mathrm{nHA} / \mathrm{COL}=2 / 1$.

In contrast to AT-MSCs, very low ALP-activity was observed for BM-MSCs (Fig. 2d) over the entire culture period, which was significantly decreased (relative to day 7) until the end of culture in all experimental constructs. Relative to BM$\mathrm{nHA} / \mathrm{COL}=0 / 1$, no significant differences were found between different constructs.

b

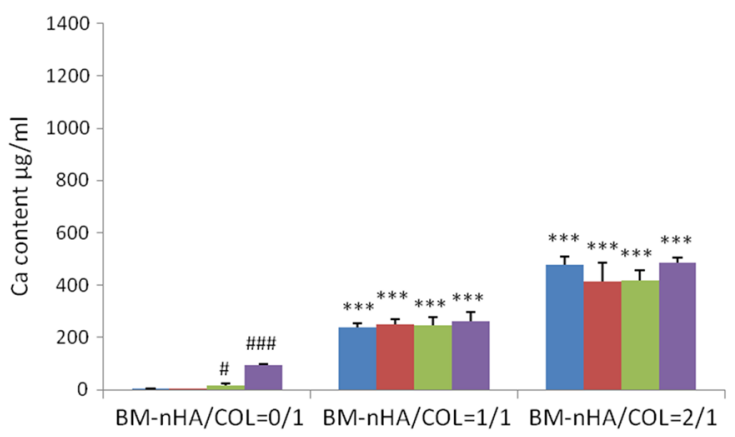

d

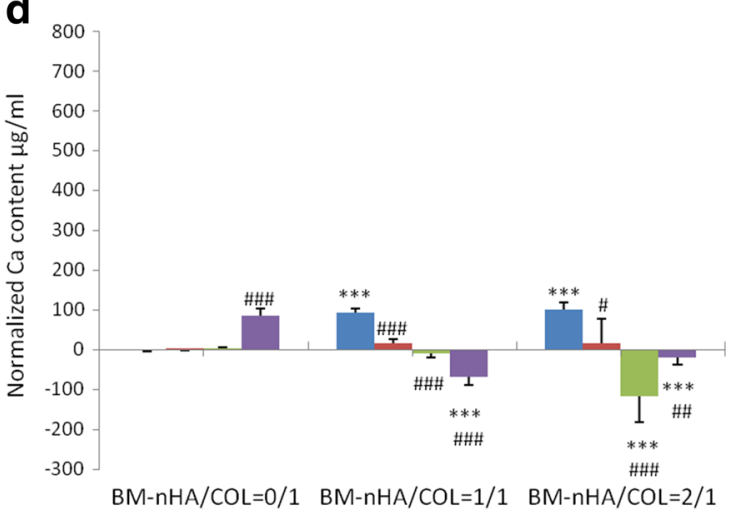

at the same time point ( $p$-values: $* p<0.05, * * p<0.01, * * * p<0.001$ ), “\#” indicates significantly different compared to day 7 ( $p$-values: ${ }^{\#} p<0.05,{ }^{\# \#} p<0.01,{ }^{\# \#} p<0.001$ ) 


\section{Calcium Deposition}

Calcium deposition results (Fig. 3a-b) were normalized for non-cellular constructs, which were treated similarly as cellular constructs. The mineralization level for both cell types was generally low. Relative to day 7, AT-MSCs showed a temporal increase in calcium deposition (Fig. 3c) for AT-nHA/COL $=1$ / 1 at day $28(p<0.05)$, and at day $35(p<0.001)$ for all experimental constructs.

BM-MSCs generally showed a decrease in mineralization (relative to day 7) starting at day 14 until the end of the culture period (Fig. 3d). Only for BM-HA/COL $=0 / 1$, an increase in mineralization was observed at day $35(p<0.001)$. Relative to $\mathrm{BM}-\mathrm{nHA} / \mathrm{COL}=0 / 1$, a significantly increased mineralization was observed for BM-nHA/COL $=1 / 1$ and BM-nHA/ $\mathrm{COL}=2 / 1(p<0.001)$ at day 7 .

\section{Gene Expression}

BMP2 AT-MSCs showed a gradual increase in BMP2 expression until day 28 , and decrease again until day 35 , irrespective of construct type (Fig. 4a). Relative to day 14, significantly higher BMP2 expression was observed for AT-nHA/COL $=0$ / 1 at day $28(p<0.01)$ and $35(p<0.05)$, for AT-nHA/COL $=1 /$ 1 at day $28(p<0.001)$ and $35(p<0.05)$, and for AT-nHA/
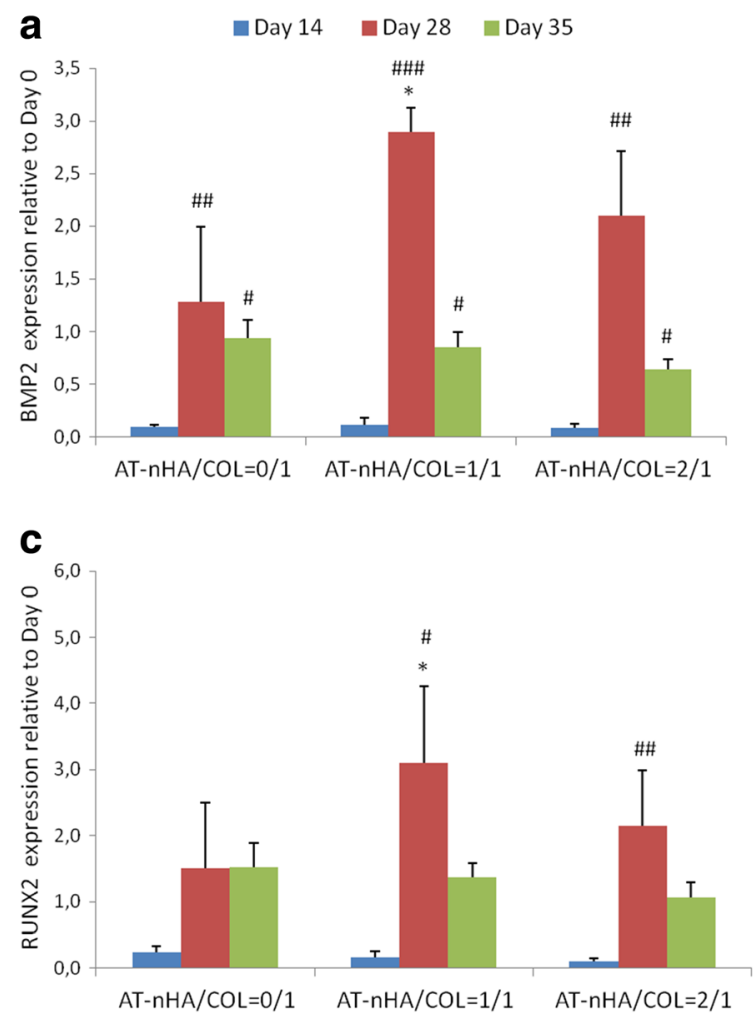

Fig. 4 Gene expression profiles of BMP2 and RUNX2. a Gene expression of BMP2 in AT-MSCs, $\mathbf{b}$ Gene expression of BMP2 in BMMSCs, $\mathbf{c}$ Gene expression of RUNX2 in AT-MSCs, $\mathbf{d}$ Gene expression of RUNX2 in BM-MSCs. The "*” indicates significantly different
$\mathrm{COL}=2 / 1$ at day $28(p<0.01)$ and $35(p<0.05)$. Relative to AT-nHA/COL $=0 / 1$, significantly higher BMP2 expression was observed for AT-nHA/COL $=1 / 1$ at day $28(p<0.05)$.

BM-MSCs showed a gradual increase in BMP2 expression until day 28 and thereafter a decrease until day 35 (Fig. 4b) for $\mathrm{BM}-\mathrm{nHA} / \mathrm{COL}=1 / 1$ and $\mathrm{BM}-\mathrm{nHA} / \mathrm{COL}=2 / 1$. Relative to day 14 , significantly higher BMP2 expression was observed for BM-nHA/COL = 1/1 and for BM-nHA/COL $=2 / 1$ at day $28(p<0.001)$. Relative to BM-nHA/COL $=0 / 1$, significantly higher BMP2 expression was observed for BM-nHA/ $\mathrm{COL}=1 / 1$ and for BM-nHA/COL $=2 / 1$ at day $28(p<0.01)$.

RUNX2 AT-MSCs showed an upregulation of RUNX2 expression after day 14, irrespective of construct type (Fig. 4c). Relative to day 14, significantly higher RUNX2 expression was observed for AT-nHA/COL $=1 / 1$ at day $28(p<0.05)$ and for AT-nHA/COL $=2 / 1$ at day $28(p<0.01)$.

BM-MSCs, showed high levels of RUNX2 expression at day 14 irrespective to construct type, which further increased only for BM-nHA/COL = 1/1 (Fig. 4d). Relative to day 14, significantly higher RUNX2 expression was observed for $\mathrm{BM}-\mathrm{nHA} / \mathrm{COL}=1 / 1$ at day $28(p<0.05)$. Relative to BM$\mathrm{nHA} / \mathrm{COL}=0 / 1$ significantly higher RUNX2 expression was observed for BM-nHA/COL $=1 / 1$ at day $28(p<0.001)$ and for BM-nHA/COL $=2 / 1$ at day $14(p<0.001)$.
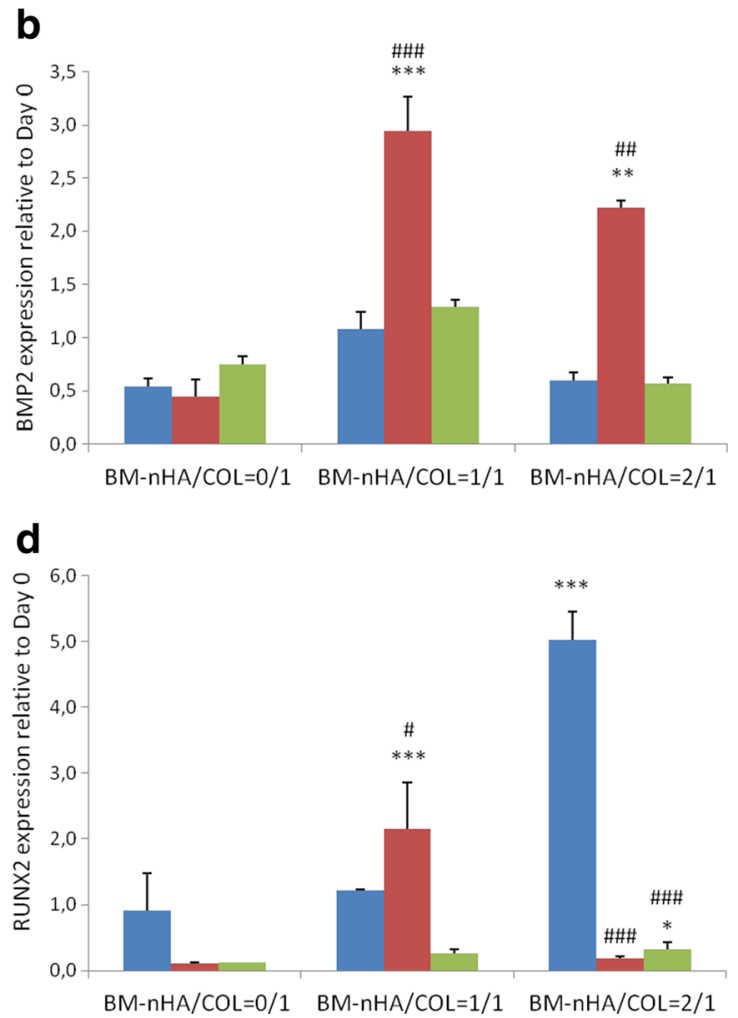

compared to $\mathrm{nHA} / \mathrm{COL}=0 / 1$ control, at the same time point ( $p$-values: $\left.{ }^{*} p<0.05,{ }^{* *} p<0.01,{ }^{* * *} p<0.001\right)$, “\#” indicates significantly different compared to day 14 ( $p$-values: ${ }^{\#} p<0.05,{ }^{\# \#} p<0.01,{ }^{\# \#} p<0.001$ ) 
Ocn AT-MSCs showed an upregulation of OCN expression starting at day 28 until day 35, except for AT-nHA/COL $=2 / 1$, for which the expression of OCN was downregulated after day 28 (Fig. 5a). Relative to day 14, significantly higher OCN expression was observed for AT-nHA/COL $=0 / 1$ at day 28 and $35(p<0.001)$, for AT-nHA/COL $=1 / 1$ at day 28 $(p<0.001)$ and $35(p<0.01)$, and for AT-nHA/COL $=2 / 1$ at day $28(p<0.001)$. Relative to AT-nHA/COL $=0 / 1$, significantly higher OCN expression was observed for AT-nHA/ $\mathrm{COL}=2 / 1$ at day $35(p<0.05)$.

BM-MSCs, showed high expression of OCN at day 14, which was downregulated toward the end of the culture period, irrespective of construct type (Fig. 5b). Relative to day 14, significantly lower OCN expression was observed for BM$\mathrm{nHA} / \mathrm{COL}=0 / 1$ at day $35(p<0.05)$, for BM-nHA/ $\mathrm{COL}=1 / 1$ at day $28(p<0.01)$ and $35(p<0.001)$ and for $\mathrm{BM}-\mathrm{nHA} / \mathrm{COL}=2 / 1$ at day 28 and $35(p<0.05)$. Relative to $\mathrm{BM}-\mathrm{nHA} / \mathrm{COL}=0 / 1$, an upregulation of OCN expression was observed for BM-nHA/COL $=1 / 1$ at day $14(p<0.05)$ and $28(p<0.01)$.

COL1 AT-MSCs showed an upregulation of COL1 expression starting at day 28 (Fig. 5c), irrespective of construct type. Significantly higher COL1 expression (relative to day 14) was observed for AT-nHA/COL $=0 / 1$ at day 28 and $35(p<0.001)$, for AT-nHA/COL $=1 / 1$ at day $28(p<0.01)$ and 35

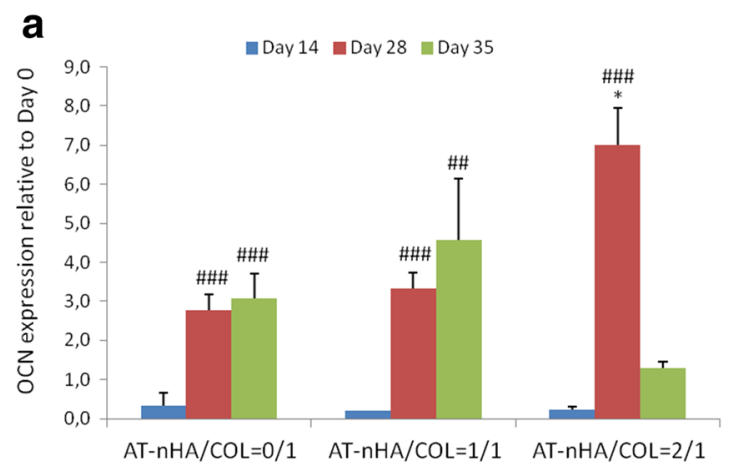

$c$

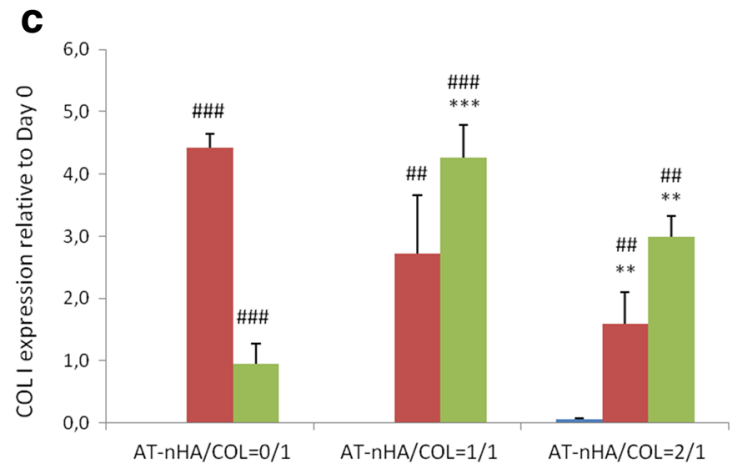

Fig. 5 Gene expression profiles of OCN and COL1. a Gene expression of OCN in AT-MSCs, $\mathbf{b}$ Gene expression of OCN in BM-MSCs, $\mathbf{c}$ Gene expression of COL1 in AT-MSCs, $\mathbf{d}$ Gene expression of COL1 in BMMSCs. The "*" indicates significantly different compared to nHA/ $(p<0.001)$, and for AT-nHA/COL $=2 / 1$ at day 28 $(p<0.01)$ and $35(p<0.01)$. Relative to AT-nHA/COL $=0 /$ 1 , the expression of COL1 was significantly higher for AT$\mathrm{nHA} / \mathrm{COL}=1 / 1$ at day $35(p<0.001)$ and for AT-nHA/ $\mathrm{COL}=2 / 1$ at day 28 and $35(p<0.01)$.

BM-MSCs showed high expression of COL1 at day 14, after which the COL1 expression was downregulated until the end of the culture period (Fig. 5d). Relative to day 14, significantly lower COL1 expression was observed for BM$\mathrm{HA} / \mathrm{COL}=0 / 1$ at day $28(p<0.05)$, for $\mathrm{BM}-\mathrm{HA} / \mathrm{COL}=1 / 1$ at day 28 and $35(p<0.01)$ and for BM-HA/COL $=2 / 1$ at day 28 and $35(p<0.01)$. Relative to $\mathrm{BM}-\mathrm{HA} / \mathrm{COL}=0 / 1$, significantly higher $\mathrm{COL} 1$ expression was for $\mathrm{BM}-\mathrm{HA} / \mathrm{COL}=1 / 1$ at day $14(p<0.01)$ and for BM-HA/COL $=2 / 1$ at day $28(p<0.01)$.

\section{Histological Analysis and Immunohistochemistry}

HE Stain HE-stained histological sections of all experimental constructs as well as HE stained sections of human bone (positive control) are presented in Fig. 6a. Results of AT-MSC constructs showed that at day 7 as well as at day 28, cells were distributed throughout the entire construct. At the periphery of constructs, the cellular density was apparently higher compared to the centre of constructs (high density cell populations are indicated with arrows in Fig. 6a-1, 2, 3, 5). The distribution of BM-MSCs in nHA/COL constructs was different at

b

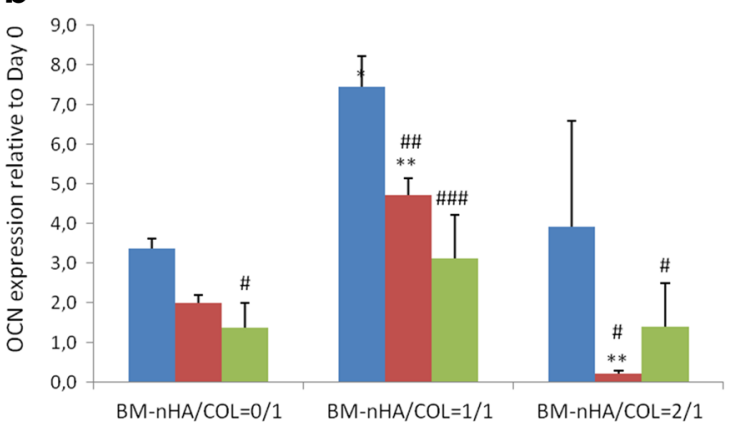

d

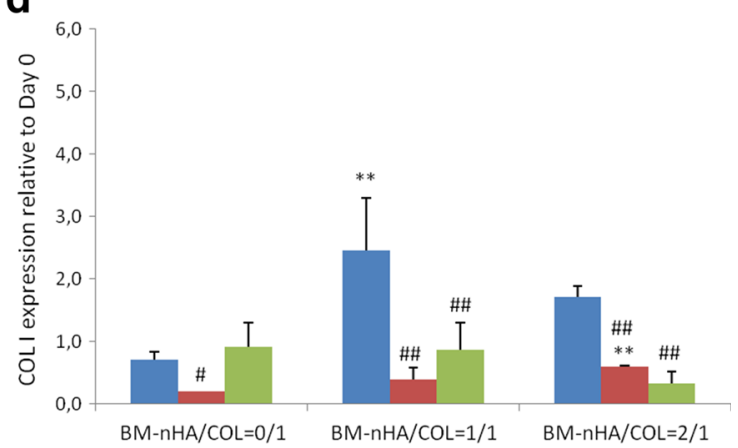

$\mathrm{COL}=0 / 1$ control, at the same time point ( $p$-values: ${ }^{*} p<0.05$, $* * p<0.01, * * * p<0.001)$, “\#” indicates significantly different compared to day 14 ( $p$-values: ${ }^{\#} p<0.05,{ }^{\# \#} p<0.01,{ }^{\# \# \#} p<0.001$ ) 

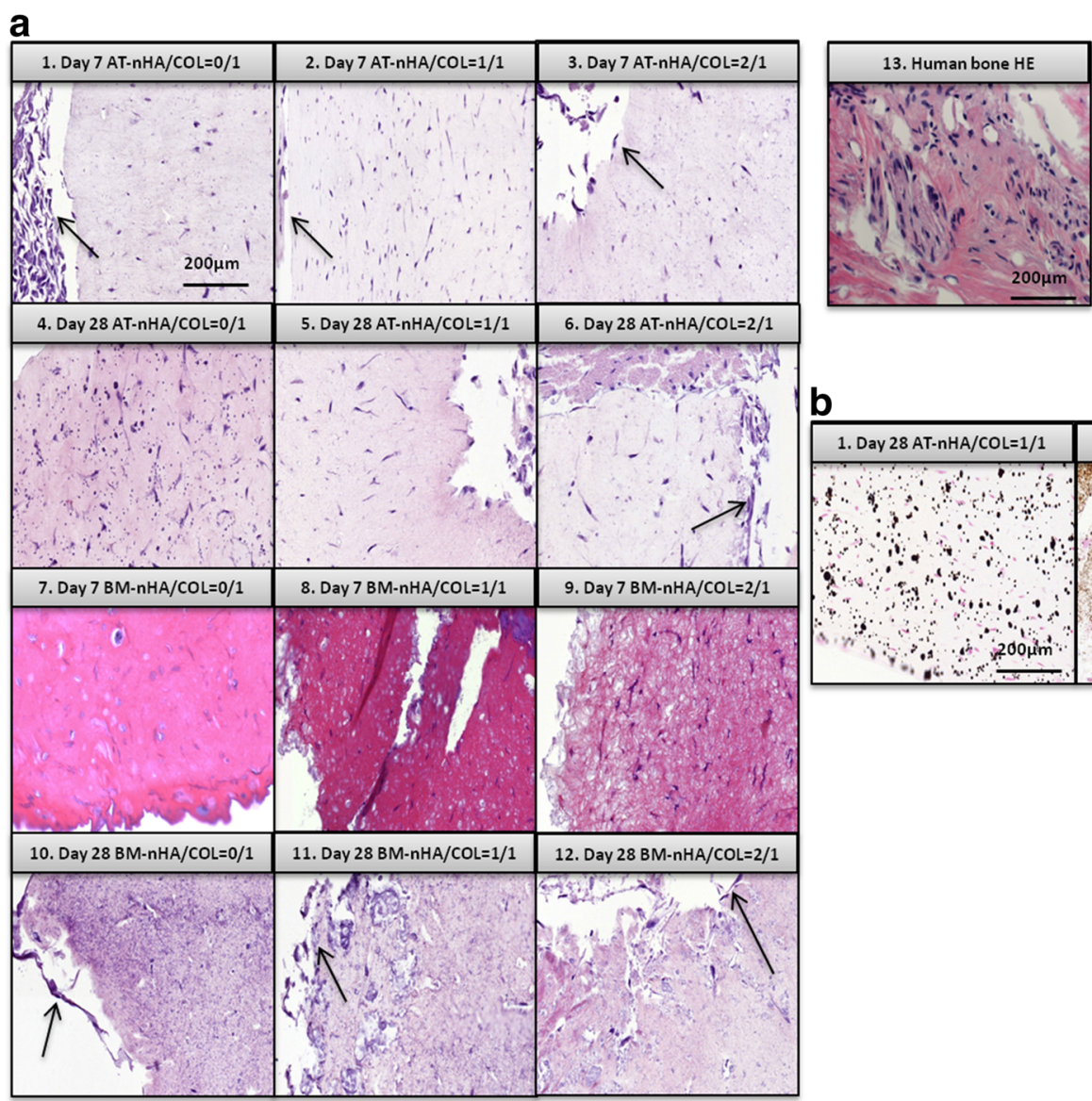

b

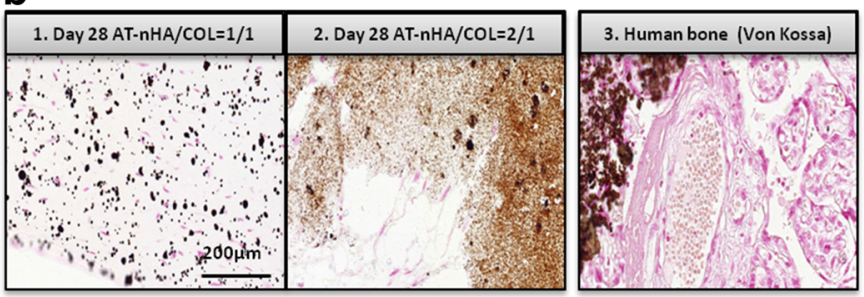

Fig. 6 a HA staining of different group of nHA/COL constructs after 7 and 28 days of culture, b Von Kossa staining of different group of nHA/COL constructs after 28 days of culture

different time points. At day 7, cells were homogeneously distributed throughout the entire construct (Fig. 6a-7, 8, 9). However, at day 28 cells were mainly located at the periphery of constructs, and only few cells were detectable in the central region (Fig. 6a-10, 11, 12).

Von Kossa Stain To monitor the mineral deposition inside the constructs, Von Kossa staining was used (Fig. 6b). Mineral deposition was only detectable for AT-nHA/COL $=1 / 1$ and AT-nHA/COL $=2 / 1$ at day 28 .

IHC-OCN Stain AT-MSCs showed detectable OCN expression at day 28, especially for AT-nHA/COL $=0 / 1$ (Fig. 7-4, 5, 6). OCN protein was homogeneously distributed throughout the entire construct. AT-MSCs were observed in these constructs with an elongated, spindle-shaped morphology (highlighted with arrows in Fig. 7-4, 5, 6). BM-MSCs showed high OCN expression at day 7, especially for BM-nHA/ $\mathrm{COL}=1 / 1$ and for BM-nHA/COL $=2 / 1$ (Figs. 7-8, 9). At day 28 , the $\mathrm{OCN}$ was still detectable for $\mathrm{BM}-\mathrm{nHA} / \mathrm{COL}=0 / 1$ and $\mathrm{BM}-\mathrm{nHA} / \mathrm{COL}=1 / 1$, but not for BM-nHA/COL $=2 / 1$ (Figs. 7-10, 11, 12).

\section{Discussion \& Conclusion}

The aim of this study was to comparatively evaluate the in vitro effect of biomimetic nHA/collagen based composite hydrogels (with different concentrations of nHA) on the behavior of MSCs, isolated from adipose tissue (AT-MSCs) and bone marrow (BM-MSCs). We hypothesized that (i) nHA/collagen based hydrogels promote the osteogenic differentiation of MSCs in nHA concentration dependent manner, and that (ii) AT-MSCs will show higher osteogenic capacities compared to BM-MSCs, because of their intrinsic proliferation and osteogenic differentiation potential in 2D in vitro cultures. This study indicated that AT-MSCs show high proliferation, differentiation and mineralization potential in $\mathrm{nHA} / \mathrm{COL}$ constructs, irrespective of nHA concentration, whereas BM-MSCs showed only marginal cell proliferation and osteogenic differentiation in all experimental $\mathrm{nHA} / \mathrm{COL}$ constructs. Based on the results of ALP activity and OCN protein level, the osteogenic differentiation of BM-MSCs started in the beginning of the culture period and for AT-MSCs at the end of the culture period. At a molecular level, both cell types showed high expression of osteogenic markers (BMP2, RUNX2, OCN or COL1) in both a nHA concentration and time dependent manner. 

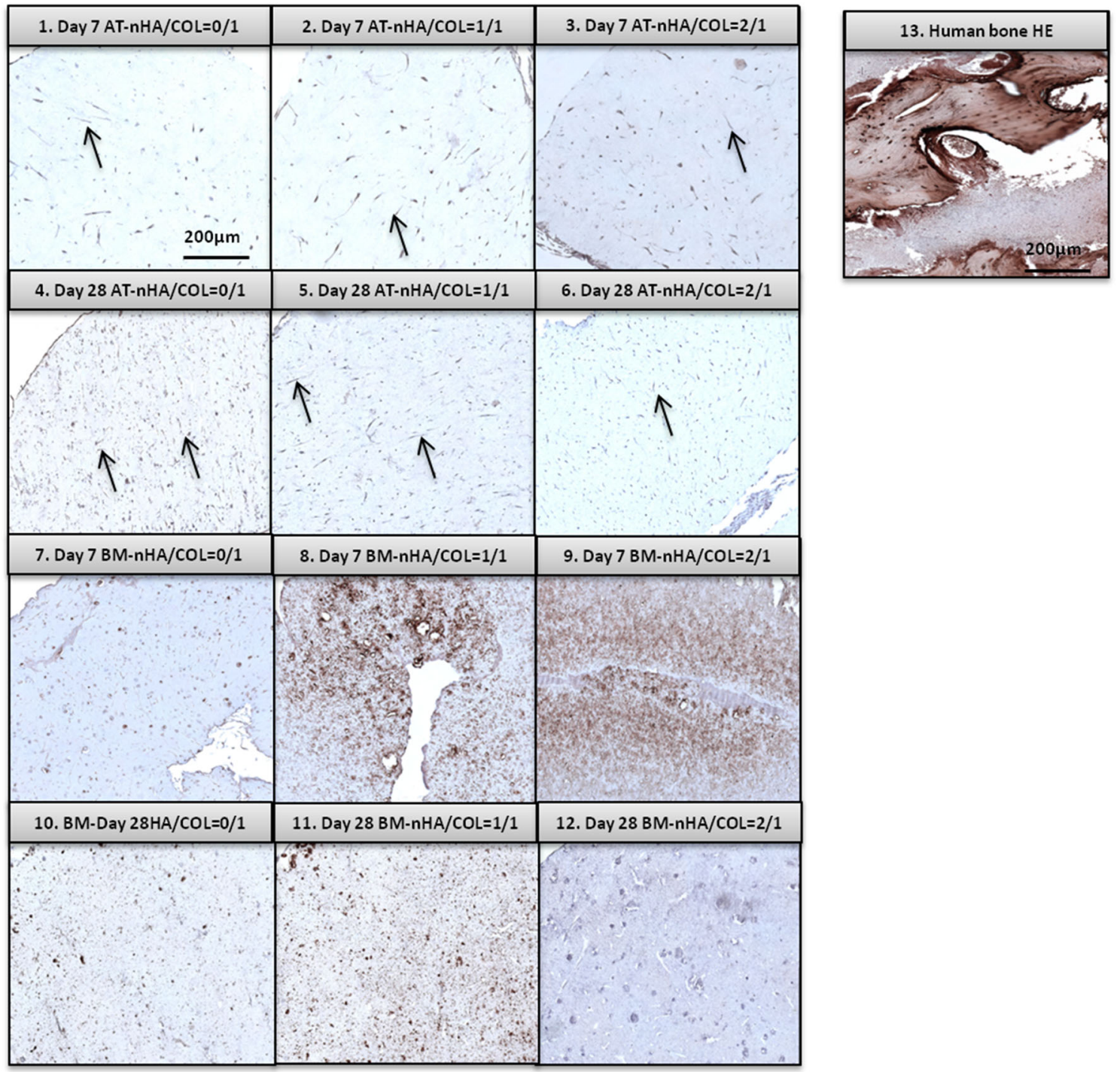

Fig. 7 Immunohistochemical staining of $\mathrm{OCN}$, in different group of $\mathrm{nHA} / \mathrm{COL}$ constructs, after 7 and 28 days of culture

At a cellular level, the material properties (different nHA/ COL ratio) did not show any substantial effect on the cellular behavior of AT-MSCs or BM-MSCs. However, apparent differences were observed between cell types, i.e. the source for MSCs. AT-MSCs showed higher proliferation and osteogenic differentiation compared to BM-MSCs. This phenomenon corroborates several earlier studies [1,23], but this study clearly demonstrates that the cellular behavior of AT-MSCs does not change in a nHA concentration dependent manner. High proliferation levels of AT-MSCs could potentially provide faster cell-cell interaction compared to BM-MSCs, and this cellular interaction in 3D micro-environment could promote subsequent AT-MSC osteogenic differentiation [23, 31]. Remarkably, BM-MSCs started to proliferate and differentiate already within the first week of culture, irrespective of nHA concentration, whereas AT-MSCs started to differentiate only after the third week of culture. Early osteogenic differentiation of BM-MSCs can be explained with faster osteocyte formation. The signaling mechanisms involved in osteocyte formation could be activated at different time points in AT-MSCs and BM-MSCs, because AT-MSCs and BM-MSCs were cultured in different (PL or FBS supplemented) osteogenic media with different content of signaling molecules [32].

Molecular analysis of osteogenic markers, i.e. BMP2 (osteoblast differentiation marker), RUNX2 (essential element for osteogenic differentiation and skeletal morphogenesis), OCN (later stage osteogenic differentiation marker) and COL1 (crucial element of connective tissue) [33-35] showed that the material properties (nHA concentration) have an effect on the gene expression pattern of these molecules. It is known that nHA play a functional role in integrin-mediated cell adhesion and signaling [36]. Cell adhesion to ECM is mediated 
by transmembrane receptors [37]. This initiates intracellular signals, and focal adhesion kinase activation [38], which play a crucial role in activation of downstream signaling. This signaling cascade can stimulate the activation of transcription factors and subsequent signal transduction [39]. For ATMSCs, the expression of BMP2, RUNX2 and COL1 was promoted by AT-nHA/COL $=1 / 1$ constructs, whereas the expression of OCN and COL1 was promoted by AT-nHA/ $\mathrm{COL}=2 / 1$ constructs.

For BM-MSCs the expression pattern of BMP2, RUNX2, OCN and COL1 was remarkably higher in BM-nHA/ $\mathrm{COL}=1 / 1$ constructs, especially in the beginning of the culture period (at day 14). This observation proved that the osteogenic differentiation of BM-MSCs starts at an earlier time points compared to AT-MSCs. Moreover, already at day 7, BM-MSCs expressed high levels of OCN, which also indicates early osteogenic differentiation of BM-MSCs. Next, ATMSCs and BM-MSCs showed a similar pattern of BMP2 expression. It has been shown that AT-MSCs can respond to BMP2 signals and express other osteogenic markers (e.g. OPN and RUNX2) [40], which indicates that AT-MSCs are a reliable cell type for future use in cell-based bone regenerative strategies.

In conclusion, AT-MSCs demonstrated higher osteogenic potential in nHA/COL based 3D micro-environments compared to BM-MSCs, in which proliferation and osteogenic differentiation were highly promoted. The proliferation and osteogenic differentiation pattern of AT-MSCs and BMMSCs was regulated in a time dependent manner, irrespective of nHA amount in the constructs. On the other hand, nHA/ COL ratios differently affected gene expression profiles of AT-MSCs and BM-MSCs. The fact that AT-MSCs showed high proliferation and mineralization is appealing for their application in future (pre-)clinical research as an alternative cell source for MSCs.

\footnotetext{
Acknowledgments This work was supported by a grant from the Dutch government to The Netherlands Institute for Regenerative Medicine (NIRM, grant No. FES0908; AH).

We would like to acknowledge Natasja van Dijk for her assistance with histological preparations.
}

\section{Compliance with Ethical Standards}

Disclosures The authors indicate no potential conflicts of interest.

Open Access This article is distributed under the terms of the Creative Commons Attribution 4.0 International License (http:// creativecommons.org/licenses/by/4.0/), which permits unrestricted use, distribution, and reproduction in any medium, provided you give appropriate credit to the original author(s) and the source, provide a link to the Creative Commons license, and indicate if changes were made.

\section{References}

1. Ma J, Beucken JJ, Both SK, Prins HJ, Helder MN, Yang F, et al. Osteogenic capacity of human BM-MSCs, AT-MSCs and their cocultures using HUVECs in FBS and PL supplemented media. Journal of tissue engineering and regenerative medicine. 2013.

2. AR, A., CT, L., \& SP, N. (2012). Bone tissue engineering: recent advances and challenges. Critical Reviews ${ }^{\mathrm{TM}}$ in Biomedical Engineering, 40(5).

3. Weiner, S., \& Wagner, H. D. (1998). The material bone: structuremechanical function relations. Annual Review of Materials Science, 28(1), 271-298.

4. Tzaphlidou, M., Fountos, G., \& Glaros, D. (2000). Bone hydroxyapatite/collagen ratio: in vivo measurements by X-ray absorptiometry. Annals of the New York Academy of Sciences, 904(1), 284-286.

5. Clarke B. Normal bone anatomy and physiology. Clinical Journal of the American Society of Nephrology. 2008; 3(Supplement 3): S131-S9.

6. Drury, J. L., \& Mooney, D. J. (2003). Hydrogels for tissue engineering: scaffold design variables and applications. Biomaterials, 24(24), 4337-4351.

7. DeVolder, R., \& Kong, H. J. (2012). Hydrogels for in vivo-like three-dimensional cellular studies. Wiley Interdisciplinary Reviews. Systems Biology and Medicine, 4(4), 351-365.

8. Serre, C., Papillard, M., Chavassieux, P., \& Boivin, G. (1993). In vitro induction of a calcifying matrix by biomaterials constituted of collagen and/or hydroxyapatite: an ultrastructural comparison of three types of biomaterials. Biomaterials, 14(2), 97-106.

9. Dhandayuthapani, B., Yoshida, Y., Maekawa, T., \& Kumar, D. S. (2011). Polymeric scaffolds in tissue engineering application: a review. International Journal of Polymer Science., 2011.

10. Alonso, M., Claros, S., Becerra, J., \& Andrades, J. (2008). The effect of type I collagen on osteochondrogenic differentiation in adipose-derived stromal cells in vivo. Cytotherapy, 10(6), 597-610.

11. Clarke, K., Graves, S., Wong, A., Triffitt, J., Francis, M., \& Czernuszka, J. (1993). Investigation into the formation and mechanical properties of a bioactive material based on collagen and calcium phosphate. Journal of Materials Science. Materials in Medicine, 4(2), 107-110.

12. LeGeros, R. Z. (2008). Calcium phosphate-based osteoinductive materials. Chemical Reviews, 108(11), 4742-4753.

13. Barradas, A. M., Monticone, V., Hulsman, M., Danoux, C., Fernandes, H., Birgani, Z. T., et al. (2013). Molecular mechanisms of biomaterial-driven osteogenic differentiation in human mesenchymal stromal cells. Integrative Biology, 5(7), 920-931.

14. Chai, Y. C., Carlier, A., Bolander, J., Roberts, S. J., Geris, L., Schrooten, J., et al. (2012). Current views on calcium phosphate osteogenicity and the translation into effective bone regeneration strategies. Acta Biomaterialia, 8(11), 3876-3887.

15. Wahl, D., \& Czernuszka, J. (2006). Collagen-hydroxyapatite composites for hard tissue repair. European Cells \& Materials, 11, 4356.

16. Geckil, H., Xu, F., Zhang, X., Moon, S., \& Demirci, U. (2010). Engineering hydrogels as extracellular matrix mimics. Nanomedicine, 5(3), 469-484.

17. Ma, J., Both, S. K., Yang, F., Cui, F.-Z., Pan, J., Meijer, G. J., et al. (2014). Concise review: cell-based strategies in bone tissue engineering and regenerative medicine. Stem Cells Transl Med., 3(1), 98-107.

18. Quarto, R., Mastrogiacomo, M., Cancedda, R., Kutepov, S. M., Mukhachev, V., Lavroukov, A., et al. (2001). Repair of large bone defects with the use of autologous bone marrow stromal cells. New England Journal of Medicine, 344(5), 385-386. 
19. Wang, R., Cui, F., Lu, H., Wen, H., Ma, C., \& Li, H. (1995). Synthesis of nanophase hydroxyapatite/collagen composite. Journal of Materials Science Letters, 14(7), 490-492.

20. Bueno, E. M., \& Glowacki, J. (2009). Cell-free and cell-based approaches for bone regeneration. Nature Reviews. Rheumatology, 5(12), 685-697.

21. Sundelacruz S, Kaplan DL, Editors. Stem cell-and scaffold-based tissue engineering approaches to osteochondral regenerative medicine. Seminars in cell \& developmental biology; 2009: Elsevier.

22. Kern, S., Eichler, H., Stoeve, J., Klüter, H., \& Bieback, K. (2006). Comparative analysis of mesenchymal stem cells from bone marrow, umbilical cord blood, or adipose tissue. Stem Cells, 24(5), 1294-1301.

23. Ma, J., Yang, F., Both, S. K., Kersten-Niessen, M., Bongio, M., Pan, J., et al. (2014). Comparison of cell-loading methods in hydrogel systems. Journal of Biomedical Materials Research Part A., 102(4), 935-946.

24. Ma, J., van den Beucken, J. J., Yang, F., Both, S. K., Cui, F.-Z., Pan, J., et al. (2010). Coculture of osteoblasts and endothelial cells: optimization of culture medium and cell ratio. Tissue Engineering Part C: Methods., 17(3), 349-357.

25. Chen, D., Zhao, M., \& Mundy, G. R. (2004). Bone morphogenetic proteins. Growth Factors, 22(4), 233-241.

26. Mosna, F., Sensebé, L., \& Krampera, M. (2010). Human bone marrow and adipose tissue mesenchymal stem cells: a user's guide. Stem Cells and Development, 19(10), 1449-1470.

27. Bongio, M., Van Den Beucken, J., Nejadnik, M., Leeuwenburgh, S., Kinard, L., Kasper, F., et al. (2011). Biomimetic modification of synthetic hydrogels by incorporation of adhesive peptides and calcium phosphate nanoparticles: in vitro evaluation of cell behavior. European Cells \& Materials, 22, 359-376.

28. Ma, J., Yang, F., Both, S. K., Prins, H.-J., Helder, M. N., Pan, J., et al. (2014). In vitro and in vivo angiogenic capacity of BM-MSCs/ HUVECs and AT-MSCs/HUVECs cocultures. Biofabrication, 6(1), 015005.

29. Robinson, T., Sutherland, I., \& Sutherland, J. (2007). Validation of candidate bovine reference genes for use with real-time PCR. Veterinary Immunology and Immunopathology, 115(1), 160-165.

30. Vaerman, J., Saussoy, P., \& Ingargiola, I. (2004). Evaluation of realtime PCR data. Journal of Biological Regulators and Homeostatic Agents, 18(2), 212-214.
31. Grellier, M., Bordenave, L., \& Amedee, J. (2009). Cell-to-cell communication between osteogenic and endothelial lineages: implications for tissue engineering. Trends in Biotechnology, 27(10), 562571.

32. Dallas, S. L., \& Bonewald, L. F. (2010). Dynamics of the transition from osteoblast to osteocyte. Annals of the New York Academy of Sciences, 1192(1), 437-443.

33. Aubin, J., Liu, F., Malaval, L., \& Gupta, A. (1995). Osteoblast and chondroblast differentiation. Bone, 17(2), S77-S83.

34. Lee, M.-H., Kim, Y.-J., Kim, H.-J., Park, H.-D., Kang, A.-R., Kyung, H.-M., et al. (2003). BMP-2-induced Runx2 expression is mediated by Dlx5, and TGF- $\beta 1$ opposes the BMP-2-induced osteoblast differentiation by suppression of Dlx 5 expression. The Journal of Biological Chemistry, 278(36), 34387-34394.

35. Hesse, E., Hefferan, T. E., Tarara, J. E., Haasper, C., Meller, R., Krettek, C., et al. (2010). Collagen type I hydrogel allows migration, proliferation, and osteogenic differentiation of rat bone marrow stromal cells. Journal of Biomedical Materials Research Part A., 94(2), 442-449.

36. Kim, K., Dean, D., Lu, A., Mikos, A. G., \& Fisher, J. P. (2011). Early osteogenic signal expression of rat bone marrow stromal cells is influenced by both hydroxyapatite nanoparticle content and initial cell seeding density in biodegradable nanocomposite scaffolds. Acta Biomaterialia, 7(3), 1249-1264.

37. Gronthos, S., Simmons, P., Graves, S., \& Robey, P. G. (2001). Integrin-mediated interactions between human bone marrow stromal precursor cells and the extracellular matrix. Bone, 28(2), 174181.

38. Gajjeraman, S., He, G., Narayanan, K., \& George, A. (2008). Biological assemblies provide novel templates for the synthesis of biocomposites and facilitate cell adhesion. Advanced Functional Materials, 18(24), 3972-3980.

39. Rouahi, M., Champion, E., Hardouin, P., \& Anselme, K. (2006). Quantitative kinetic analysis of gene expression during human osteoblastic adhesion on orthopaedic materials. Biomaterials, 27(14), 2829-2844

40. Helder, M. N., Knippenberg, M., Klein-Nulend, J., \& Wuisman, P. I. (2007). Stem cells from adipose tissue allow challenging new concepts for regenerative medicine. Tissue Engineering, 13(8), $1799-1808$. 